\title{
Analysis of Labeling and Clearance of Lung Surfactant Phospholipids in Rabbit
}

\author{
EVIDENCE OF BIDIRECTIONAL SURFACTANT FLUX BETWEEN \\ LAMELLAR BODIES AND ALVEOLAR LAVAGE
}

\author{
Mikko Hallman, Benita L. Epstein, and Louis Gluck, University of California, \\ San Diego, Department of Pediatrics, School of Medicine, La Jolla, \\ California 92093
}

\begin{abstract}
A B S T RACT Turnover and clearance of lung surfactant phospholipids were studied with particular reference to myoinositol-induced perturbation in the acidic phospholipids. Administration of myoinositol decreased $\left[{ }^{3} \mathrm{H}\right]$ palmitate and $\left[{ }^{32} \mathrm{P}\right]$ phosphate incorporation into phosphatidylglycerol by $80-90 \%$ in whole lung, and by $94-99 \%$ in lamellar bodies and in alveolar lavage. The increased incorporation of radioactive isotopes into phosphatidylinositol following myoinositol, was inverse to the decrease in phosphatidylglycerol incorporation. Myoinositol treatment affected neither content nor labeling of phosphatidylcholine or disaturated phosphatidylcholine as studied within $50 \mathrm{~h}$ of administration. Phosphatidylglycerol was pulse labeled by intravenous [32 P]phosphate and $\left[{ }^{3} \mathrm{H}\right]$ palmitate, followed by myoinositol. The biological half-lives of phosphatidylglycerol in the microsomal fraction, lamellar bodies, and alveolar lavage were 1.6, 4.6, 5.4 h (with ${ }^{3} \mathrm{H}$ ), and 2.8, 6.5, 7.0 h (with ${ }^{32} \mathrm{P}$ ), respectively.

${ }^{32} \mathrm{P}$-labeled lung surfactant tracer was applied to the airways in saline suspension and the clearance of phospholipid radioactivity was measured in alveolar lavage, alveolar macrophages, lamellar bodies and lung homogenates. The clearance rates of phosphatidylcholine, disaturated phosphatidylcholine, phosphatidylglycerol, and phosphatidylinositol as studied in whole lung over $6 \mathrm{~h}$ were $3.4-5.8 \% \mathrm{~h}$. Only a small amount of phospholipid radioactivity was recovered in the alveolar macrophage fraction (including bis[monoacylglycerol]phosphate). Phospholipid radioactivity in alveolar lavage fell to $40-70 \%$ of the maximum during the 1 st $h$, and to $5-18 \%$ over the next
\end{abstract}

Received for publication 31 October 1980 and in revised form 27 April 1981.
$6 \mathrm{~h}$. During $2 \mathrm{~h}$ after the application of phospholipids, the radioactivity in the lamellar body fraction increased, and the specific radioactivities approached those in alveolar lavage. The association of phosphatidylglycerol with lamellar bodies was unaffected by myoinositol.

Phosphatidylinositol entered more slowly than did phosphatidylglycerol from microsomes to the alveolar lavage fraction, and from alveolar lavage to lamellar bodies. These differences may be of importance regarding the poor performance of phosphatidylinositolcontaining surfactant at birth. Further investigations are needed to clarify the possible role for the postulated bidirectional surfactant flux between the lamellar body and alveolar lavage fractions in maintaining the activity of surfactant.

\section{INTRODUCTION}

Phospholipids of lung surfactant are synthesized in the endoplasmic reticulum membranes of type II alveolar cells. Subsequently, they appear in intracellular lamellar inclusion bodies and enter into the alveolar spaces (1-4). The mechanism of clearance of alveolar phospholipids is unclear, possibly involving phospholipase digestion by alveolar macrophages or other structures, removal by ciliary epithelium of the airways or by the lymphatics. The biosynthesis, intracellular transport, and half-life of the major surfactant phospholipid, phosphatidylcholine (PC), ${ }^{1}$ and its surface active component, disaturated PC, has been studied using autoradiography and biochemical tech-

\footnotetext{
${ }^{1}$ Abbreviations used in this paper: BMP, bis-(monoacylglycerol)phosphate; PC, phosphatidylcholine; PG, phosphatidylglycerol; PI, phosphatidylinositol; INO, myoinositol; TLC, thin-layer chromatography.
} 
niques involving measurement of specific radioactivity in defined cell fractions (3-7). According to Jobe (6), the biological half-life of surfactant associated PC is $16-18 \mathrm{~h}$, using radioactive palmitate or glycerol as tracers. The apparent half-lives using $\left[{ }^{3} \mathrm{H}\right]$ choline or $\left[{ }^{32} \mathrm{P}\right]$ phosphate were longer, suggesting sustained utilization, rather than pulse label of the precursor $(6,7)$.

The studies of turnover and clearance of surfactant components recently have received increasing attention largely because of therapeutic trials of installing surface active material into the airways in respiratory distress syndrome $(8-11)$.

In addition to $\mathrm{PC}$, lung surfactant contains other characteristic phospholipids. In particular, phosphatidylglycerol (PG) is present in uniquely high concentration. Recent evidence indicates that PG is important in surfactant function and that its absence may even precipitate RDS at birth. This is considered to be due to the property of low compressibility of surfactant containing PG at low surface tension, as compared to surfactant with prominent phosphatidylinositol (PI) and no PG (12). Using $\left[{ }^{3} \mathrm{H}\right]$ glycerol and $\left[{ }^{14} \mathrm{C}\right]$ palmitate as precursors, the biological half-life of PG (10-14 h), is somewhat shorter than that of PC, whereas the apparent half-life of PI associated with surfactant is longer $(20-36 \mathrm{~h})(7)$.

As recently shown, myoinositol (INO) prevents synthesis of surfactant PG by enhancing that of PI and thereby exhausting the availability of cytidine diphosphate-diacylglycerol required for phosphatidylglycerolphosphate synthesis (13). INO also was effective in vivo, causing a virtual halt of surfactant PG formation within a few minutes (13). In the present study, INO was given to pulse label PG and to inhibit its synthesis, in order to study the turnover and clearance in more detail.

\section{METHODS}

Male New Zealand White rabbits weighing $1.2 \pm 0.1 \mathrm{~kg}$ were used. Before the injection of the isotopes the animals were kept without food or water for 6-8 h. INO was administered as described previously (13). To ensure rapid inhibition of PG synthesis in the pulse-labeling experiments, $12 \%$ (wt/vol) INO was infused into a marginal ear vein at a rate of 125 $\mathrm{ml} / \mathrm{h}$ for $5 \mathrm{~min}$, followed by $45 \mathrm{ml} / \mathrm{h}$ for $25 \mathrm{~min}$, and $17 \mathrm{ml}$ $\mathrm{h}$ for $90 \mathrm{~min}$, using a Harvard infusion pump (Harvard Apparatus, Millis, Mass.). During infusions longer than $2 \mathrm{~h}$, $12 \%$ INO was given at a rate of $7 \mathrm{ml} / \mathrm{h}$. After the infusion food and $7 \%$ INO were given ad lib. The liquid consumption was $145 \pm 18 \mathrm{ml} / \mathrm{kg}$ per d (controls $140 \pm 15 \mathrm{ml} / \mathrm{kg}$ per d). An occasional animal who drank $<100 \mathrm{ml} / \mathrm{kg}$ per d was withdrawn from the experiment. The above dosage schedule maintained serum INO levels at least 10 times higher than in the controls (unpublished observations).

For application of the surface active material the animals were anesthetized using Ketamine HCL (Parke-Davis, Detroit, Mich.), $30 \mathrm{mg} / \mathrm{kg}$, and Xylazine (Haver-Lochart,
Shawnee, Kan.), $5 \mathrm{mg} / \mathrm{kg}$, s.c. If necessary, half of the dosage was given again.

The isotopes, $\left[9,10-{ }^{3} \mathrm{H}\right]$ palmitic acid, ortho $\left[{ }^{32} \mathrm{P}\right]$ phosphate and $\left[2-{ }^{3} \mathrm{H}\right]$ glycerol were purchased from New England Nuclear, Boston, Mass. For the in vivo labeling experiments, the animals received $0.3 \mathrm{mCi} / \mathrm{kg}$ of $\left[{ }^{3} \mathrm{H}\right]$ palmitate $(6)$ and $0.6 \mathrm{mCi} / \mathrm{kg}$ of ${ }^{32} \mathrm{P}$ as a continuous intravenous infusion for $1 \mathrm{~min}$.

Isolation and application of the surface active material into the airways. The rabbits $(0.5-0.8 \mathrm{~kg})$ received $5-8 \mathrm{mCi}$ of ${ }^{32} \mathrm{P}$ i.v. 36-42 $\mathrm{h}$ before death. Some animals additionally received $2 \mathrm{mCi}$ of either $\left[{ }^{3} \mathrm{H}\right]$ palmitate or $1 \mathrm{mCi}$ of $\left[{ }^{3} \mathrm{H}\right]-$ glycerol i.v. 6-7 $\mathrm{h}$ before death. The alveolar lavage was obtained as described below. However, only two rather than five successive lavages were performed. After sedimentation of the cells, the lavage fluid was centrifuged at $100,000 \mathrm{~g}_{\mathrm{av}}$ for $3 \mathrm{~h}$. The resulting pellet was freeze-dried and stored at $-20^{\circ} \mathrm{C}$ if necessary, and was homogenized in $75 \mathrm{mM} \mathrm{NaCl}$ before the application. The total quantity of phospholipid applied to the airways was $100-250 \mathrm{nmol}$; i.e., $4 \%$ or less of the total phospholipid pool that was recovered by alveolar lavage (PC+ PG + PI associated radioactivity: 135,000$380,000 \mathrm{cpm}{ }^{32} \mathrm{P}, 200,000 \mathrm{cpm}\left[{ }^{3} \mathrm{H}\right]$ palmitate, or $28,000 \mathrm{cpm}$ $\left[{ }^{3} \mathrm{H}\right]$ glycerol).

For isolation of PG-devoid surface active material, the animals received INO, starting $48-52 \mathrm{~h}$ before death. The contents of the acidic phospholipids were as follows (normal surfactant in parentheses): PG, $0.4 \pm 0.1 \%$ of phospholipid-P, $n=7(6.1 \pm 0.5 \%, n=9)$; PI, $9.7 \pm 0.6 \%(5.1 \pm 0.4 \%)$. The other phospholipids were not significantly different as compared between controls and INO-treated animals (13). For surfactant application, polyethylene tubing, i.d. $0.584 \mathrm{~mm}$, o.d. 0.965 $\mathrm{mm}$ (Clay Adams, Parsippany, N. J.) was introduced into the airways, $1.5-2 \mathrm{~cm}$ distal to the thyroid cartilage, using a size $19 \times 1 \frac{1}{2}$ inch infusion needle. The catheter was advanced $7-8 \mathrm{~cm}$. The surface active material in $0.3-0.5 \mathrm{ml}$ of saline suspension was introduced while the rabbit was in a supine elevated position. The dead space of the catheter was flushed with $0.4 \mathrm{ml}$ of $75 \mathrm{mM} \mathrm{NaCl}$. Application of the material often was followed by tachypnea for a few minutes, but it had no effect on blood gases (carbon dioxide tension, arterial oxygen tension).

In three instances the phospholipid radioactivities were measured in the tubing and syringe used for the application, the central airways (trachea, main bronchi), and in the left and right lungs separately. In these cases alveolar lavage was not performed. The tubing and syringe contained $6.3(4.5-8.2) \%$, the central airways $2.9(1.0-4.3) \%$, the left lung $0.2(0.0-0.3) \%$, and the right lung $84.6(78.0-89.2) \%$ of the radioactivity. The recovery of the radioactivity was 94 $(90-99) \%$. India ink was added twice to the surfactant suspension applied to the airways. Staining appeared evenly distributed within the lower and middle lobes of the right lung, but little if any staining was seen in the right upper lobe or in the left lung.

Isolation, purity, and recovery of the fractions. Alveolar lavage was performed through a catheter in the trachea, by introducing $15-18 \mathrm{ml} / \mathrm{kg}$ of $\mathrm{M} \mathrm{NaCl}$ into the airways, and then gently withdrawing it. The procedure was repeated five times. The recovery of the fluid was $96 \pm 2 \%$. Visibly bloody washes were excluded from the analysis. The lavage fluid was centrifuged at $150 \mathrm{~g}$ for $10 \mathrm{~min}$, and the supernate was the alveolar lavage fraction. The pellet was dispersed in $0.15 \mathrm{M} \mathrm{NaCl}$ and the alveolar macrophage fraction was sedimented at $150 \mathrm{~g}$ for $10 \mathrm{~min}$. On the basis of Giemsastained smears of the pellet, $>90 \%$ of the cells were macrophages.

The alveolar lavage preceded the isolation of the sub- 
cellular fractions. The microsomal fraction and lamellar bodies were isolated as described earlier (14). According to succinate dehydrogenase activity measurements there was $3.7 \pm 0.4 \%(n=5)$ of mitochondrial protein contamination in microsomes and $<5 \%$ contamination in the lamellar bodies. The absence of sphingomyelin $(<0.5 \%$ of total phospholipids) in the lamellar body fraction was in striking contrast to the presence of this phospholipid in the microsomal fraction [14.1 $\pm 0.9 \%(n=26)$ of total phospholipids].

The degree of contamination of the lamellar body fraction by alveolar lavage phospholipids was estimated by adding 32P-labeled lavage fluid to the residual lung that contained no radioactivity. The lamellar body fraction subsequently isolated contained $5(4-7) \%(n=3)$ of the added radioactivity.

Since alveolar lavage was routinely performed before the isolation of the organelles, and because the estimated recovery of total lavageable phospholipids by the present alveolar lavage procedure was $70 \%$ (see below), the estimated contamination of the lamellar body fraction by alveolar lavage return was $7(5-8) \%(n=3)$. This estimate is based upon a pool size of lamellar body PC of $2.7 \pm 0.3(n=38) \mu \mathrm{mol}$ and of alveolar lavage PC of $9.0 \pm 1.0 \mu \mathrm{mol}(n=38)$, using the present methods.

The possibility that some phospholipids originally present in intracellular lamellar bodies associate with the alveolar lavage fraction during the lavage procedure was studied as shown in Table I. Repeated lavage continued to yield decreasing disaturated $\mathrm{PC} /$ sphingomyelin ratio and decreasing phospholipid/protein ratio, suggesting a significant recovery of material from extra-lamellar body sources. On the other hand, the specific activities of disaturated PC and PG were unaffected. This suggests that the release of the lamellar body contents into the lavage fluid was not significant during the lavage procedure.

The recovery of lamellar bodies was estimated by adding ${ }^{32} \mathrm{P}$-labeled fresh lamellar bodies to the residual lung, followed by the measurement of the radioactivity in the subsequently isolated lamellar body fraction. The recovery, 20(16$20) \%(n=3)$, may be an overestimate since some of the lung cells can remain unbroken during the homogenization. Study of nuclear count of the Papanicolau-stained smears of lung homogenate revealed $6(3-7) \%(n=3)$ unbroken cells. To estimate the recovery of phospholipids by alveolar lavage, we performed the lavage 12 times, and got progressively less material. The phospholipid content recovered in the first five washings was $68-73 \%(n=3)$ of that obtained in the 12 lavages (cf. ref. 9).

Lipid analysis. Lipids were extracted as described by Bligh and Dyer (15), and the individual phospholipids were separated by two-dimensional thin-layer chromatography (TLC) as described previously (14). The phospholipids were recovered after iodine visualization, analyzed for ${ }^{32} \mathrm{P}$ and ${ }^{3} \mathrm{H}$ radioactivity (14) and for phosphorus content (16). Disaturated PC was measured according to Mason et al. (17) The recovery calculated for each assay using [2-palmitoyl 9,10- ${ }^{3} \mathrm{H}$ ]-L- $\alpha$-dipalmitoyl PC (Applied Science Laboratories, State College, $\mathrm{Pa}$.) standard was $81 \pm 2 \%$. The product recovered from the column ran as a single spot on TLC, and 97-98\% of total fatty acids were saturated by gas chromatography analysis (14).

Others. For electron microscopy the pellets of isolated lamellar bodies were fixed with $2.5 \%$ glutaraldehyde in $0.1 \mathrm{M}$ phosphate ( $\mathrm{pH} \mathrm{7.4)}$ for $2 \mathrm{~h}$ and postfixed with $1 \% \mathrm{OsO}_{4}$ for $1 \mathrm{~h}$. After a rinse with a phosphate buffer, the pellets were dehydrated with graded concentrations of acetone, and embedded in resin containing araldite 502, dodecenyl succinic anhydride, and 2,4,6,tri(dimethylaminomethyl)phenol $(25: 25: 1 \mathrm{vol} / \mathrm{vol} / \mathrm{vol})$. Thin sections, cut with a diamond $\mathrm{knife}$ were examined in a Zeiss EM-9S transmission electron microscope (Carl Zeiss, Inc., New York). Succinate dehydrogenase (E.C. 1.3.99.1) was measured according to Sottocasa et al. (18) and protein according to Lowry et al. (19). Results are presented as means $\pm \mathrm{SE}$, and statistical significance was calculated using the $t$ test. The statistical difference between the slopes of the linear regression lines was calculated by analysis of covariance.

\section{RESULTS}

The labeling of phospholipids in lung fractions. Effect of myoinositol. INO treatment drastically changed PG and PI pools, whereas PC, disaturated PC, phosphatidylserine, and phosphatidylethanolamine were unaffected (data not shown, cf ref. 13). Since PG and PI were frequently in the nonsteady state, the radioactivity associated with these lipids was expressed on the basis of total PC.

TABLE I

Recovery of Phospholipids and Phospholipid Radioactivity in Lamellar Bodies and in Alveolar Lavage*

\begin{tabular}{|c|c|c|c|c|c|c|}
\hline & \multirow[b]{2}{*}{$\begin{array}{l}\text { Total phospha- } \\
\text { tidylcholine }\end{array}$} & \multirow[b]{2}{*}{$\begin{array}{l}\text { Phospholipid/ } \\
\text { protein }\end{array}$} & \multirow[b]{2}{*}{$\begin{array}{l}\text { Disaturated phos- } \\
\text { phatidylcholine/ } \\
\text { sphingomyelin }\end{array}$} & \multirow{2}{*}{$\begin{array}{c}\text { Disaturated } \\
\text { phosphatidyl- } \\
\text { choline } \\
\text { (\% total PC) }\end{array}$} & \multicolumn{2}{|c|}{ Specific radioactivity } \\
\hline & & & & & $\begin{array}{c}\text { Disaturated } \\
\text { phosphatidyl- } \\
\text { choline }\end{array}$ & $\begin{array}{l}\text { Phosphatidyl- } \\
\text { glycerol }\end{array}$ \\
\hline & $\mu \mathrm{mol}$ & umol/mg & & & \multicolumn{2}{|c|}{ cpm/nmol phospholipid-P } \\
\hline Lamellar bodies & 3.20 & 7.8 & 151 & 64 & 22.6 & 14.8 \\
\hline \multicolumn{7}{|l|}{ Alveolar lavage: } \\
\hline lst & 3.23 & 4.9 & 56 & 62 & 3.1 & 2.7 \\
\hline 2nd & 3.20 & 3.5 & 35 & 62 & 2.2 & 2.3 \\
\hline 3rd & 1.94 & 2.0 & 21 & 57 & 3.2 & 2.6 \\
\hline 4th & 1.31 & 1.4 & 17 & 55 & 2.7 & 2.7 \\
\hline 5 th & 0.86 & 0.7 & 14 & 54 & 3.3 & 2.8 \\
\hline
\end{tabular}

* $1 \mathrm{~h}$ after $\left[{ }^{3} \mathrm{H}\right]$ palmitate i.v. the animals were sacrificed, and the above analyses were performed in lamellar body and alveolar lavage fractions. The results are the means of three independent experiments. 
Fig. 1 shows the specific activities of $\mathrm{PC}$, disaturated PC, PG, and PI in total lung homogenate after administration of $\left[{ }^{3} \mathrm{H}\right]$ palmitate and ${ }^{32} \mathrm{P}$. INO inhibited PG, stimulated PI, and had no effect on PC. These effects were independent of the interval between the administration of INO and the radioactive precursor.

${ }^{32} \mathrm{P}$ was preferentially incorporated into phosphatidylserine and phosphatidylethanolamine. INO had no effect on these specific activities either. Since the results were similar to those obtained by Jobe et al. (7), they are not presented.

Fig. 2 shows the specific activities of PI and PG in microsomes and Fig. 3 illustrates the labeling of the four phospholipids in lamellar bodies and in alveolar lavage following administration of $\left[{ }^{3} \mathrm{H}\right]$ palmitate. INO profoundly inhibited PG, stimulated PI, and had no effect on PC (microsomal data for PC not shown).

Pulse labeling of phosphatidylglycerol. To abolish continuous PG labeling, INO was added $10 \mathrm{~min}$ after $\left[{ }^{3} \mathrm{H}\right]$ palmitate and $90 \mathrm{~min}$ after ${ }^{32} \mathrm{P}$.

Figs. 2 and 4 show specific activities of $\left[{ }^{3} \mathrm{H}\right] \mathrm{PG}$ in microsomes, in lamellar bodies and in alveolar lavage. In lamellar bodies and in alveolar lavage the maximum activities were attained within 1 and $3 \mathrm{~h}$, respectively. The specific radioactivities fell shortly after the maximum.

The biological half-lives. The $t_{1 / 2}$ were measured by studying the rate of decay of the specific radioactivity up to $50 \mathrm{~h}$ after administration of the isotope. As studied in lung homogenate (PC and pulse labeled PG) and microsomes, the decay lines had two slopes. Only

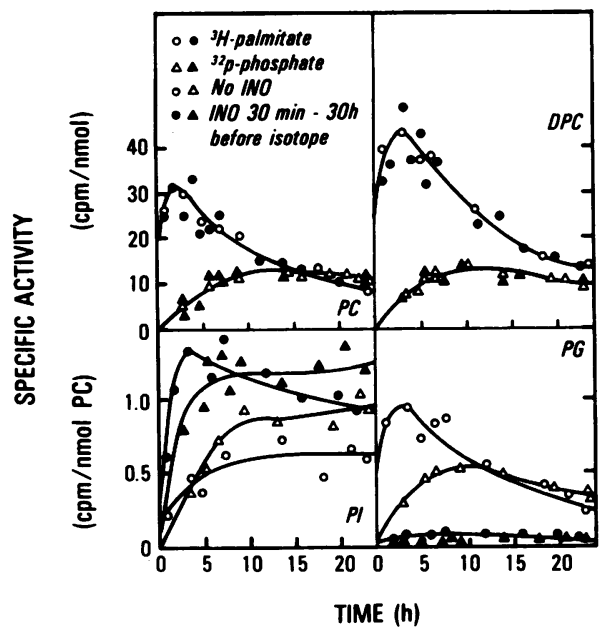

FIGURE 1 Labeling of lung parenchymal phospholipids after $0.3 \mathrm{mCi} / \mathrm{kg}$ of $\left[{ }^{3} \mathrm{H}\right]$ palmitate and $0.6 \mathrm{mCi} / \mathrm{kg}$ of ${ }^{32} \mathrm{P}$. i.v. The figures shown are derived by combining the measurements in lung homogenate and alveolar lavage: the sum of radioactivities was divided by the sum of phospholipid pools. INO was given as described in Methods. The curves are fit by eye.

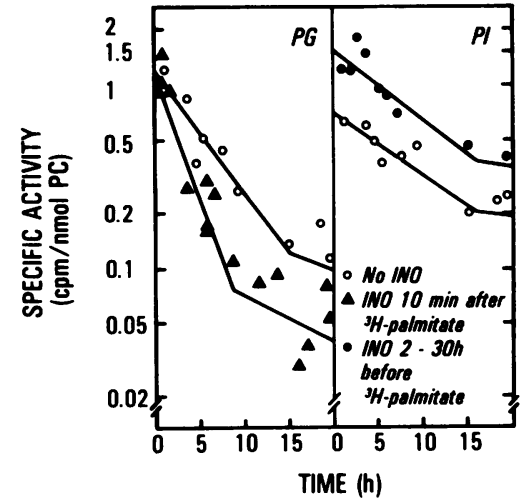

FIGURE 2 Disappearance of the $\left[{ }^{3} \mathrm{H}\right]$ palmitate labeled PG and PI from lung microsomes after $0.3 \mathrm{mCi} / \mathrm{kg}$ of $\left[{ }^{3} \mathrm{H}\right] \mathrm{pal}-$ mitate i.v. (zero time). The lines were calculated from an exponential regression curve fit to the data by the method of least squares (time from $10 \mathrm{~min}$ to $50 \mathrm{~h}$ ).

the initial decay rates are shown in Table II. Using ${ }^{32} \mathrm{P}$, the gradual increase in radioactivity $20-40 \mathrm{~h}$ following administration of the isotope hampered the calculation of $t_{1 / 2}$.

The $t_{1 / 2}$ of PG, using the pulse-labeling technique, were shorter than those obtained without INO. In a preliminary report, the $t_{1 / 2}$ were somewhat longer than in the present study, since the specific activities of the short plateau were included in the calculations (20). INO had no effect on the $t_{1 / 2}$ of PC.

Application of surfactant to the airways. To study the clearance of surfactant phospholipids, the ${ }^{32} \mathrm{P}$ labeled surface active material was applied to the airways. After the application, lung lavage, alveolar macrophages, residual lung homogenate, lamellar bodies, microsomes, and mitochondria were isolated

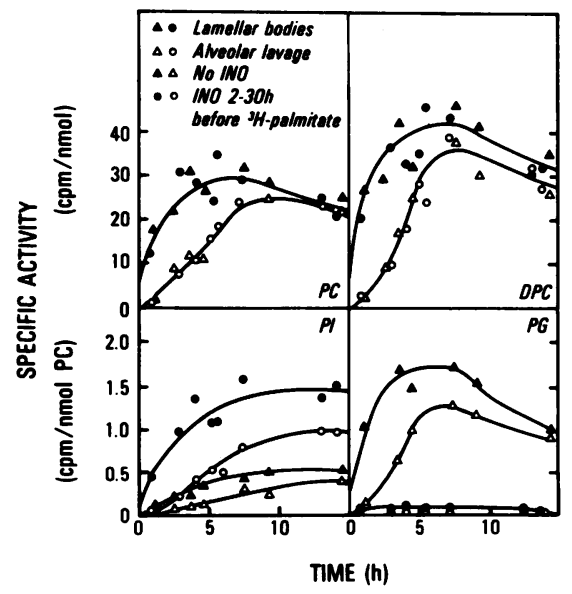

FIGURE 3 Labeling of phospholipids in lamellar bodies and in alveolar lavage after $\left[{ }^{3} \mathrm{H}\right]$ palmitate $(0.3 \mathrm{mCi} / \mathrm{kg})$ was given intravenously (zero time), followed by INO $10 \mathrm{~min}$ later. The curves are best fit by eye. 


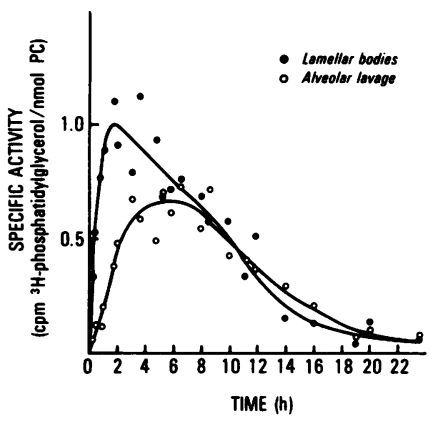

FIgUre 4 Pulse labeling of surfactant PG. $\left[{ }^{3} \mathrm{H}\right]$ palmitate $(0.3$ $\mathrm{mCi} / \mathrm{kg}$ ) was given intravenously (zero time), followed by INO $10 \mathrm{~min}$ later. The curves are best fit by eye.

and analyzed for radioactivity associated with $\mathrm{PC}$, disaturated PC, PG, PI, and bis-(monoacylglycerol)phosphate (BMP).

After the preliminary experiments it became evident that the specific activities in microsomes and in mitochondria were low and frequently undetectable. Therefore during subsequent measurements these fractions no longer were analyzed.

Five different treatment groups were used, namely: (a) normal surfactant given to normal animals, (b) PG deficient surfactant given to normal animals, (c) normal surfactant given to animals that received INO beginning $30 \mathrm{~min}$ before the application, $(d)$ normal surfactant given to animals treated with INO for 36$48 \mathrm{~h}$, (e) PG deficient surfactant given to animals treated with INO for 36-48 h.

Fig. 5 reveals the ultrastructure of the lamellar body fraction in treatment group 5. The morphology of the lamellar body fraction was similar to the corresponding fraction that was isolated in the absence of surfactant application (data not shown).

Figs. 6 and 7 show the distribution of the specific activity of the four phospholipids in alveolar lavage and in lamellar bodies. To facilitate comparison between the fractions, the specific activity of the alveolar lavage 15-30 s after surfactant application served as a reference (relative specific activity $100 \%$ ). Because of the relatively small number of experiments, statistical comparison between the five groups was not possible. However, as shown in Figs. 6 and 7, neither the quality of the surfactant applied nor the surfactant status of the recipient seemed to have a significant effect on the redistribution and disappearance of the phospholipids.

TABLE II

Apparent $t_{1 / 2}(h)$ of Phospholipids in Lung Fractions. * Effect of INO

\begin{tabular}{|c|c|c|c|c|c|c|c|c|c|}
\hline & & \multicolumn{2}{|c|}{ Lung homogenate } & \multicolumn{2}{|c|}{ Microsomes } & \multicolumn{2}{|c|}{ Lamellar bodies } & \multicolumn{2}{|c|}{ Alveolar lavage } \\
\hline & & Palmitate & Phosphate & Palmitate & Phosphate & Palmitate & Phosphate & Palmitate & Phosphate \\
\hline \multirow[t]{2}{*}{ PG } & $A \oint$ & $\begin{array}{c}5.9 \\
(0.797)\end{array}$ & $\begin{array}{c}7.5 \\
(0.659)\end{array}$ & $\begin{array}{c}1.6 \\
(0.907)\end{array}$ & $\begin{array}{c}2.8 \\
(0.650)\end{array}$ & $\begin{array}{c}4.6 \\
(0.932)\end{array}$ & $\begin{array}{c}6.5 \\
(0.875)\end{array}$ & $\begin{array}{c}5.4 \\
(0.942)\end{array}$ & $\begin{array}{c}7.0 \\
(0.798)\end{array}$ \\
\hline & $\mathrm{B}^{\prime \prime}$ & $\begin{array}{c}12.8 \\
(0.878)\end{array}$ & ๆ & $\begin{array}{c}4.6 \\
(0.765)\end{array}$ & ๆ & $\begin{array}{c}11.5 \\
(0.857)\end{array}$ & ๆ & $\begin{array}{c}14.8 \\
(0.989)\end{array}$ & ๆ \\
\hline $\mathrm{PC}^{* *}$ & & $\begin{array}{c}14.0 \\
(0.975)\end{array}$ & ๆ & $\begin{array}{c}6.1 \\
(0.829)\end{array}$ & ๆ & $\begin{array}{c}14.9 \\
(0.997)\end{array}$ & ๆ & $\begin{array}{c}17.9 \\
(0.960)\end{array}$ & ๆ \\
\hline Disaturated $\mathrm{PC}^{* *}$ & & $\begin{array}{c}12.5 \\
(0.957)\end{array}$ & ๆ & N.M. & N.M. & $\begin{array}{c}15.7 \\
(0.997)\end{array}$ & I & $\begin{array}{c}17.2 \\
(0.960)\end{array}$ & ๆ \\
\hline \multirow[t]{2}{*}{ PI } & A $\sharp$ & ๆ & ๆ & $\begin{array}{c}8.1 \\
(0.945)\end{array}$ & ๆ & ๆ & ๆ & $\begin{array}{c}25.4 \\
(0.799)\end{array}$ & ף \\
\hline & $\mathbf{B}^{\prime \prime}$ & I & ๆ & $\begin{array}{c}8.8 \\
(0.928)\end{array}$ & ๆ & $\begin{array}{c}23.9 \\
(0.630)\end{array}$ & ๆ & $\begin{array}{c}28.7 \\
(0.867)\end{array}$ & ๆ \\
\hline
\end{tabular}

${ }^{*} \mathrm{~T}_{1 / 2}$ of the phospholipids labeled with $\left[{ }^{3} \mathrm{H}\right]$ palmitate and ${ }^{32} \mathrm{P}$ were calculated from the regression equations of the data partly shown in Figs. 1-4. The $r$ values for the regression equations are given in parentheses.

t Alveolar lavage and lung homogenate combined.

INO was started (as described in the METHODS) $90 \mathrm{~min}$ after ${ }^{32} \mathrm{P}$ and $10 \mathrm{~min}$ after $\left[{ }^{3} \mathrm{H}\right]$ palmitate.

"No INO.

IT The data was inadequate to determine the $t_{1 / 2}$.

** The decay in the presence and absence of INO was combined, since the $t_{1 / 2}$ as compared between these two groups were similar $(P>0.4)$.

\# I INO was started $30 \mathrm{~min}$ to $30 \mathrm{~h}$ before the isotopes. 


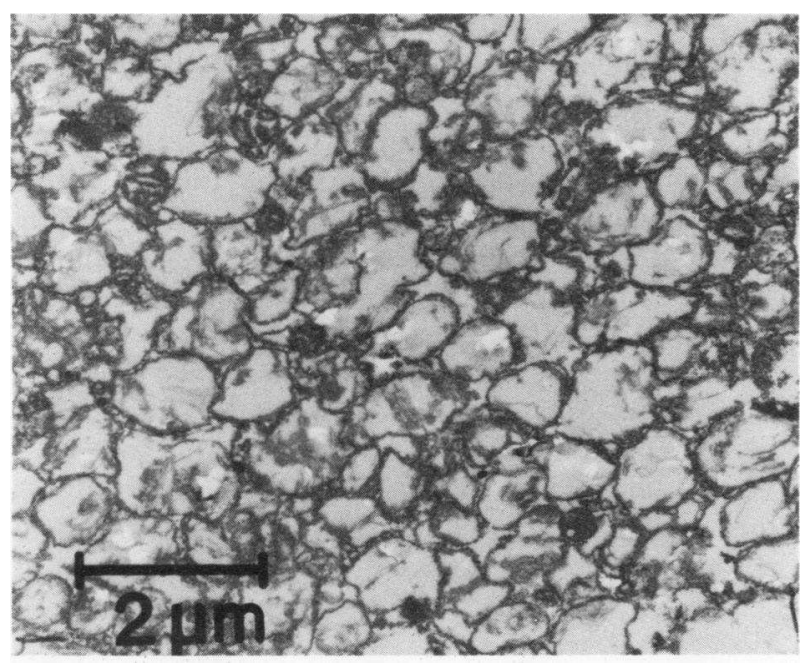

FIGURE 5 Electron micrograph of the lamellar body fraction. The animal was treated with INO for $48 \mathrm{~h}$, and PG deficient surfactant was applied to the airways $1 \mathrm{~h}$ before killing.

The relative specific activities exhibited an apparently linear change during the first hour. Therefore, the changes in the specific activities were further evaluated by analysis of covariance. For statistical comparison, the five treatment groups were combined. The radioactivity associated with lamellar body PI tended to increase more slowly than did that of PG, PC, or disaturated PC (F ratio between 7.5 and 2.5\%).

Inhibition of PG synthesis by INO had little effect on the distribution of PG label between alveolar lavage and lamellar bodies, but apparently decreased PG labeling, as studied $6 \mathrm{~h}$ after the application. Furthermore, $6 \mathrm{~h}$ after the application of PG-depleted surfactant to the airways of the normal rabbit, the specific activities of PI in surfactant fractions were four to six times higher than those of PG, whereas at the time of the application the specific activity of PI exceeded that of PG by 25-55-fold.

In some cases double labeled surface active material (two experiments with ${ }^{32} \mathrm{P}$ and $\left[{ }^{3} \mathrm{H}\right]$ palmitate, two experiments with ${ }^{32} \mathrm{P}$, and $\left[{ }^{3} \mathrm{H}\right]$ glycerol-labeled surfactant) was applied, and the specific activities of PC, disaturated PC, and PG were measured in alveolar lavage and in lamellar bodies, $30 \mathrm{~s}, 1 \mathrm{~h}$, and $2 \mathrm{~h}$ after the application. $\left[{ }^{3} \mathrm{H}\right]$ palmitate $/{ }^{32} \mathrm{P}$ and $\left[{ }^{3} \mathrm{H}\right]$ glycerol $/{ }^{32} \mathrm{P}$ ratios were calculated for individual phospholipids in the different fractions. It was found that the ratios remained within the methodological error, $\pm 5 \%$ (data not shown).

Table III lists the recovery of ${ }^{32} \mathrm{P}$, associated with PC and disaturated PC from alveolar lavage, lamellar bodies, residual lung homogenate, and alveolar macrophages. The results obtained from five different treatment groups have been combined. In addition, the

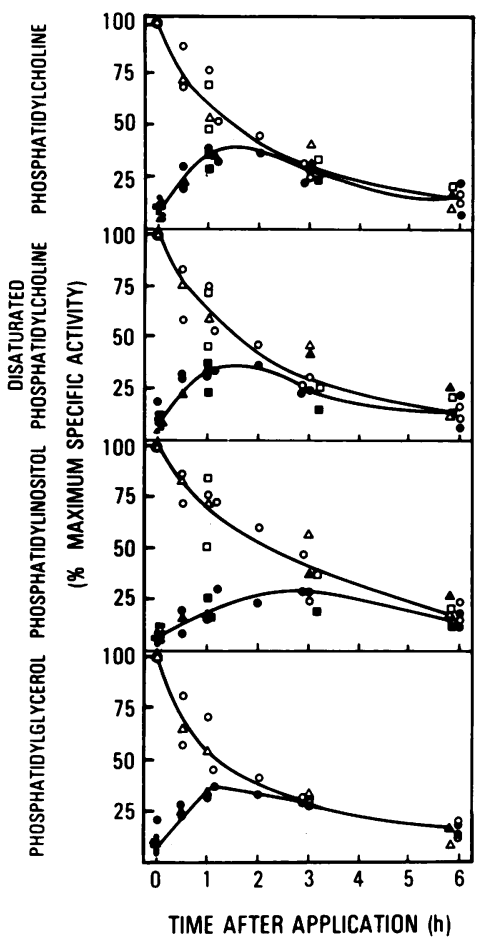

Figure 6 Clearance of ${ }^{32} \mathrm{P}$-labeled lung surfactant from the alveolar lavage fraction (open symbols), after the application of lung surfactant to the airways. The animals were studied in groups of two or three rabbits. Each time one rabbit was killed 15-30 s after the application. The specific activity of alveolar lavage phospholipids at this time was considered to be at maximum (100\%). The other specific activities were expressed as the percentage of the maximum. The absolute specific activities of PG and PI were expressed as counts per minute per nanomole of PC. The experiments with normal surfactant applied to normal animals are shown by circles, and those with PG-devoid surfactant given to normal animals are shown by squares. The triangles illustrate the experiments, where normal surfactant was applied to animals that received intravenous INO, starting $30 \mathrm{~min}$ before surfactant application. The curves are fit by eye.

estimates of the total radioactivities have been included. These figures are based on measurements of the recoveries, and of the contamination of lamellar bodies and alveolar lavage fractions. The calculated increase in the lamellar body associated radioactivity accounted for about half of alveolar phospholipid clearance during the first $2 \mathrm{~h}$. The redistribution of PG and PI after application of the labeled surfactant was similar to that of disaturated PC and PC (data not shown).

BMP associated with the alveolar macrophage fraction contained the following radioactivity (expressed in percentage of alveolar macrophage PG counts; treatment groups 1,3 , and 4): 15-30 s after the application, $65 \pm 10 \%$; $30 \mathrm{~min}, 44 \pm 5 \%$; $60-70 \mathrm{~min}, 83 \pm 17 \%$; $2 \mathrm{~h}, 71 \% ; 170-190 \mathrm{~min}, 68 \pm 15 \% ; 6 \mathrm{~h}, 108 \pm 11 \%(P$ $<0.01$ as compared with the $15-30 \mathrm{~s}$ data). The relative 


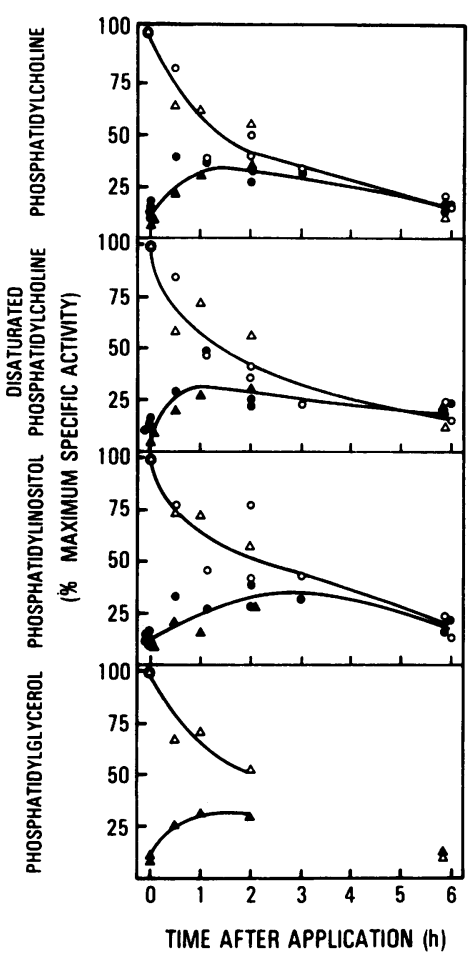

Figure 7 Clearance of ${ }^{32} \mathrm{P}$-labeled lung surfactant from alveolar lavage fraction (open symbols) and appearance to lamellar body fraction (closed symbols), after the application of lung surfactant to the airways of rabbits treated with INO for 36 to $44 \mathrm{~h}$. During the experiment 12\% INO was given intravenously at $7 \mathrm{ml} / \mathrm{h}$. The circles illustrate experiments with PG-devoid surfactant, and the triangles those with normal surfactant. For further details, see Fig. 5. radioactivity of alveolar macrophage BMP (in percentage of $P G$ radioactivity) was two to six times higher than the relative radioactivity of surfactant-associated BMP. On the other hand, BMP content was higher in alveolar macrophages than in surfactant $(10.9 \pm 0.7 \%$ of total phospholipids, vs. $1.0 \pm 0.1 \%$ ). The radioactivity of alveolar macrophage PG, expressed in percentage of alveolar macrophage disaturated PC radioactivity, did not significantly change (data not shown).

The clearance of individual phospholipids from the whole lung were calculated using linear regression analysis. For PG clearance, only group 1 was analyzed. The clearance rates of individual phospholipids ( $r$ values for the regression lines are given in parentheses) were as follows: PC $4.2 \% \mathrm{~h},(r=0.890)$, disaturated PC $5.3 \% / \mathrm{h}(r=0.905)$, PG $5.8 \% / \mathrm{h}(r=0.725)$, and PI $3.4 \% / \mathrm{h}(r=0.667)$.

\section{DISCUSSION}

According to the present study there is a bidirectional surfactant flux between the lamellar body fraction and the surfactant recovered by alveolar lavage. The data, suggesting a "backward" flux of surfactant from the alveolar spaces to the lamellar inclusion bodies derives from experiments using radioactive surfactant phospholipid applied to the airways and pulse labeling of the surfactant phospholipid in vivo. Besides the entry of the phospholipid from the airways into the lamellar body fraction, the labeled phospholipid applied to the airways may associate with the lamellar bodies with several other possible mechanisms: $(a)$ the lamellar

TABLE III

The Percentage Recovery of PC and Disaturated PC (DPC) Radioactivity in the Lung Fractions after the Application of ${ }^{32}$-labeled Surfactant into the Airways

\begin{tabular}{|c|c|c|c|c|c|c|c|c|c|c|}
\hline \multirow{2}{*}{$\begin{array}{l}\text { Time after } \\
\text { application }\end{array}$} & \multicolumn{2}{|c|}{ Alveolar lavage } & \multicolumn{2}{|c|}{ Lamellar bodies } & \multicolumn{2}{|c|}{ Homogenate } & \multicolumn{2}{|c|}{ Alveolar macrophages } & \multicolumn{2}{|c|}{ Recovery* } \\
\hline & PC & DPC & PC & DPC & PC & DPC & PC & DPC & PC & DPC \\
\hline $15-30 \mathrm{~s}$ & $\begin{array}{c}53.2 \pm 2.0 \\
(76.0) \downarrow\end{array}$ & $\begin{array}{c}52.5 \pm 1.9 \\
(75.0)\end{array}$ & $\begin{array}{c}1.5 \pm 0.3 \\
(1.8) \S\end{array}$ & $\begin{array}{c}1.5 \pm 0.4 \\
(1.8)\end{array}$ & $\begin{array}{c}27.4 \pm 1.4 \\
(4.6)^{n}\end{array}$ & $\begin{array}{c}26.9 \pm 1.6 \\
(4.4)\end{array}$ & $0.3 \pm 0.1$ & $0.3 \pm 0.0$ & $80.9 \pm 1.7$ & $79.7 \pm 2.0$ \\
\hline $30 \mathrm{~min}$ & $\begin{array}{c}38.9 \pm 2.0 \\
(55.6)\end{array}$ & $\begin{array}{c}38.1 \pm 2.0 \\
(54.4)\end{array}$ & $\begin{array}{c}2.8 \pm 0.2 \\
(9.8)\end{array}$ & $\begin{array}{c}2.9 \pm 0.5 \\
(10.4)\end{array}$ & $\begin{array}{c}38.7 \pm 1.8 \\
(22.0)\end{array}$ & $\begin{array}{c}37.1 \pm 1.3 \\
(20.8)\end{array}$ & $0.3 \pm 0.0$ & $0.3 \pm 0.0$ & $77.9 \pm 2.8$ & $75.5 \pm 2.9$ \\
\hline $60-70 \min$ & $\begin{array}{c}28.3 \pm 2.5 \\
(40.4)\end{array}$ & $\begin{array}{c}29.5 \pm 2.7 \\
(42.1)\end{array}$ & $\begin{array}{c}4.5 \pm 0.2 \\
(19.1)\end{array}$ & $\begin{array}{c}4.1 \pm 0.3 \\
(16.9)\end{array}$ & $\begin{array}{c}47.3 \pm 2.4 \\
(35.2)\end{array}$ & $\begin{array}{c}45.8 \pm 2.7 \\
(33.2)\end{array}$ & $0.5 \pm 0.1$ & $0.4 \pm 0.0$ & $76.1 \pm 3.4$ & $75.7 \pm 3.2$ \\
\hline $120 \mathrm{~min}$ & $\begin{array}{c}21.9 \pm 1.6 \\
(31.2)\end{array}$ & $\begin{array}{c}20.5 \pm 1.4 \\
(29.3)\end{array}$ & $\begin{array}{c}4.3 \pm 0.3 \\
(19.2)\end{array}$ & $\begin{array}{c}4.5 \pm 0.3 \\
(19.9)\end{array}$ & $\begin{array}{c}52.3 \pm 3.4 \\
(43.0)\end{array}$ & $\begin{array}{c}45.3 \pm 2.9 \\
(36.5)\end{array}$ & $0.4 \pm 0.1$ & $0.3 \pm 0.0$ & $74.6 \pm 5.0$ & $66.1 \pm 3.9$ \\
\hline $\begin{array}{l}2 \mathrm{~h} 50 \mathrm{~min}- \\
\quad 3 \mathrm{~h} 10 \mathrm{~min}\end{array}$ & $\begin{array}{c}16.4 \pm 1.3 \\
(23.4)\end{array}$ & $\begin{array}{c}15.4 \pm 1.7 \\
(22.0)\end{array}$ & $\begin{array}{c}3.7 \pm 0.2 \\
(17.0)\end{array}$ & $\begin{array}{c}4.3 \pm 0.4 \\
(19.8)\end{array}$ & $\begin{array}{c}53.0 \pm 3.7 \\
(46.0)\end{array}$ & $\begin{array}{c}49.4 \pm 3.5 \\
(42.8)\end{array}$ & $0.6 \pm 0.1$ & $0.5 \pm 0.1$ & $70.0 \pm 4.9$ & $60.9 \pm 5.5$ \\
\hline $\begin{array}{c}5 \mathrm{~h} 45 \mathrm{~min}- \\
6 \mathrm{~h}\end{array}$ & $\begin{array}{l}8.1 \pm 1.6 \\
(11.5)\end{array}$ & $\begin{array}{l}8.4 \pm 1.7 \\
(12.0)\end{array}$ & $\begin{array}{c}3.1 \pm 0.9 \\
(14.6)\end{array}$ & $\begin{array}{c}3.4 \pm 0.9 \\
(16.0)\end{array}$ & $\begin{array}{c}46.3 \pm 3.8 \\
(42.9)\end{array}$ & $\begin{array}{c}40.0 \pm 2.9 \\
(36.4)\end{array}$ & $0.4 \pm 0.0$ & $0.4 \pm 0.1$ & $54.8 \pm 3.8$ & $48.8 \pm 4.0$ \\
\hline
\end{tabular}

* The sum of the radioactivity in alveolar lavage, alveolar macrophages and in homogenate.

t The calculated percentage radioactivity in alveolar lavage: Percentage radioactivity in alveolar lavage/0.7.

$\$$ The calculated percentage radioactivity in lamellar bodies: $5[\mathrm{~B}-(\mathrm{A} / 0.7-\mathrm{A}) 0.05]$, where $\mathrm{A}=$ percentage radioactivity in alveolar lavage, $\mathrm{B}=$ percentage radioactivity in lamellar bodies.

"The calculated radioactivity in residual lung homogenate: $\mathrm{C}-\mathrm{A} / 0.7+\mathrm{A}$, where $\mathrm{A}=$ percentage radioactivity in alveolar lavage, $\mathrm{C}=$ percentage radioactivity in homogenate. 
body fraction may be contaminated with the alveolar lining material; $(b)$ continuous breakdown and synthesis of surface active phospholipids may enhance the label in the lamellar inclusion bodies at the expense of the extracellular lining layer; $(c)$ exchange, rather than transfer of intact phospholipid molecules may take place between the alveolar lining layer and the lamellar bodies; and $(d)$ the added surface active material may be cleared by a mechanism different from that of endogenous phospholipids.

Using radioactive markers, the estimated contamination of the lamellar body fraction by phospholipids recovered by bronchoalveolar lavage was $7 \%$. Moreover, there was no evidence that the alveolar lavage returns contained phospholipids released from intracellular lamellar bodies during our lavage procedure. This excludes the possibility that the virtual isotope equilibrium found between phospholipids recovered from the lamellar body and alveolar lavage fractions after surfactant application into airways, was caused by the contamination.

In the present experiments new PG synthesis was inhibited, in order to exclude the possibility that the alveolar phospholipid appears in the lamellar body PG fraction after its breakdown and resynthesis. Despite inhibition of synthesis, the distribution of PG between alveolar lavage and lamellar body fractions was unaffected. On the other hand, the present experiments demonstrated that some phosphate moiety of alveolar phospholipid may be (re)utilized for synthesis of surfactant phospholipids. However, the mechanism cannot contribute to the labeling of the lamellar body phospholipids during the first hour after surfactant application.

The possibility of exchange of phospholipid components rather than the entry of whole molecules from one fraction to another is excluded by the finding that the phospholipid applied to the airways appeared at a similar rate in the lamellar bodies regardless of the isotope $\left({ }^{32} \mathrm{P},\left[{ }^{3} \mathrm{H}\right]\right.$ palmitate, $\left[{ }^{3} \mathrm{H}\right]$ glycerol $)$ used for the label.

The present results are thus consistent with the findings of Oyarzun et al. (9) suggesting that the alveolar clearance of dipalmitoyl PC liposomes does not necessarily involve phospholipase activity. According to our study, an estimated half of the alveolar clearance during the first $2 \mathrm{~h}$ after the application of phospholipid to the airways was due to entry of the phospholipids into the lamellar body fraction. This figure, however, may not be quite accurate, since the methods used for estimation of the pool sizes of the surfactant fractions are subject to experimental error. The pool(s) into which about half of the phospholipids entered, remains to be identified.

Interestingly, alveolar macrophages contained only a trace of phospholipid radioactivity, indicating that these cells did not significantly contribute to the rapid clearance (21). However, it is still possible that some surfactant phospholipid is broken down or metabolized by alveolar macrophages. The finding that there was only a modest increase in BMP labeling in alveolar macrophages, and that this increase was not associated with preferential decrease in PG labeling, argues against the alternative that surfactant PG serves as the precursor of BMP. Therefore, it is likely that the precursor of BMP, PG (22), is synthesized in alveolar macrophages de novo.

According to Gil and Magno (23), filling of one lung under pressure with macromolecule-containing solutions increases the formation of pinocytotic vesicles in alveolar cells, an apparent augmentation of normal phenomenon, that possibly contributes to increased clearance of alveolar material (23). In the present study the phospholipids were introduced in $<1 \mathrm{ml}$ of saline, and the preparation presented $<4 \%$ of the recipient's alveolar phospholipids. Although the physical form of the preparation was probably different from surfactant in situ, it lowered the surface tension $<10 \mathrm{dyn} / \mathrm{cm}$ on a modified Wilhelmy balance, and similar surface active material was effective in surfactant substitution therapy $(8,11)$. On the basis of biochemical identity, it is likely that the surface active material that was applied was cleared by the same mechanism(s) as is the endogeneous surface active material, although it is uncertain whether the clearance rates are identical, particularly since we were unable to demonstrate whether all the material reached the alveolar spaces or whether some of it lined the more central airways. However, the trachea and the main bronchi contained only small amounts of radioactivity.

After the pulse labeling in vivo, the lamellar body associated PG attained maximum specific activity by one hour after administering the isotope. During the 2nd $h$ the specific activity remained rather constant (apparently due to a continuing supply of PG from the membranes of the endoplasmic reticulum). During the 2nd h, however, the specific activity of PG in alveolar lavage rose to $\sim 50 \%$ of the specific activity of the lamellar bodies, suggesting that about half of the lamellar body phospholipids, i.e., half of the alveolar lavage pool, was released into the alveoli (Fig. 4). Despite this, the half-lives of PG, calculated on the basis of decay curves, were similar in lamellar body and alveolar lavage fractions. This is not explained by a continuing supply of PG from the microsomes. The apparent discrepancy may be explained by assuming the existence of a bidirectional surfactant flux between the alveolar lavage and lamellar body fractions, an assumption that is in good agreement with our findings on the clearance of the surface active material applied to the airways.

Present evidence indicates that various factors, such 
as mode of ventilation, drugs affecting autonomic nervous system, and prostaglandins may induce rapid changes in surfactant recovered by alveolar lavage $(9$, 24-26). The possible involvement of the postulated surfactant flux from alveoli to lamellar bodies needs to be considered in further studies documenting rapid changes in surfactant pools.

Niden (27) has demonstrated that type II cells take up carbon particles placed in the alveolar lumen, suggesting phagocytic function. There are apparent similarities in the hydrolytic enzyme composition between lysosomes and lamellar bodies (28). In addition, phospholipase activities seem to associate with lamellar bodies $(29,30)$. However, both phospholipase $A$ and phosphatidate phosphohydrolase are apparently involved in biosynthesis rather than catabolism of phospholipids. If lamellar bodies represent both intracellular storage of surfactant and a site of its degradation, it is feasible to postulate the presence of two types of lamellar bodies with different functions. Our observation that incubation of radioactive lamellar body fraction (labeled with ${ }^{32} \mathrm{P}$-phospholipid that was applied to the airways) for $1 \mathrm{~h}$ at $37^{\circ} \mathrm{C}$ in vitro, released $<10 \%$ of PC associated radioactivity, suggests low phospholipase activity. Therefore, the possibility that lamellar bodies are involved in surfactant catabolism seems unlikely.

The alveolar lining of surface active material consists of tubular myelin, common myelin figures, and, at least in fetal animals, apparently intact lamellar bodies (31, 32 ). Although the properties and particularly the role of tubular myelin remains uncertain, there is evidence suggesting that it represents surface active material brought to an inactive state (33). A morphological study reveals continuity between tubular myelin and the concentric lamellae of the lamellar bodies (32). However, it is unknown, whether the postulated bidirectional surfactant flux between the intra- and extracellular fractions takes place through direct continuity between lamellar bodies and alveolar lining, or whether the extracellular surfactant is cleared by pinocytotic vesicles, that may associate with the lamellar body fraction. Further investigation is required to elucidate the possible role of the rapid interaction between the intraand extracellular surfactant in maintaining the physicochemical activity of surfactant.

Using the present pulse-labeling technique the halflives of PG in microsomes and in surfactant fractions were remarkably short. According to previous (7) and present results, PI emerged more slowly from the microsomes into surfactant fractions, and from the alveoli into the lamellar bodies, than did the PG. It is possible that the long apparent half-life of surfactant associated PI is for the most part due to its prolonged transfer from the site of biosynthesis to the surfactant fractions. Furthermore, the actual half-lives of sur- factant PC probably are shorter than those obtained in the present and previous studies $(6,7)$.

The altered status of the acidic phospholipids had little effect on the turnover of individual surfactant phospholipids under the present experimental conditions. This does not necessarily mean that the turnover of a phospholipid always is independent of the others. However, specific proteins may prove to be important determinants in transport and turnover of surfactant phospholipids (34).

The observed difference between PG and PI in their ability to associate with surfactant could influence surfactant composition in a nonsteady state. Indeed, using the present INO model, the increase in surfactant PI takes place more gradually than does the decrease in PG (unpublished results). Especially at birth, when the fluid filling of alveoli is promptly replaced by air, the proper function of surfactant is critical.

Considering the postulated importance of the acidic phospholipids in promoting the surface adsorption and in preventing the collapse of the major surfactant component $(35,36)$, the slow association of PI with the alveolar lavage fraction could be another factor explaining the poor performance of surfactant devoid of PG at birth.

\section{ACKNOWLEDGMENTS}

This work was supported by National Institutes of Health grants HD 10622, and Specialized Center of Research HL 23584. The authors are grateful to Dr. Jerrold Abraham for preparing the electron micrographs, and to Miss Carole Petty for secretarial assistance.

\section{REFERENCES}

1. Macklin, C. C. 1954. The pulmonary alveolar mucoid film and the pneumonocytes. Lancet. 266: 1099-1104.

2. Kikkawa, Y., K. K. Motoyama, and L. Gluck. 1968. Study of the lungs of fetal and newborn rabbits. Am. J. Pathol. 52: $177-192$.

3. Askin, F. B., and C. Kuhn. 1971. The cellular origin of pulmonary surfactant. Lab. Invest. 25: 260-267.

4. Chevalier, G., and A. J. Collet. 1972. In vivo incorporation of choline- ${ }^{3} \mathrm{H}$, leucine $-{ }^{3} \mathrm{H}$ and galactose $-{ }^{3} \mathrm{H}$ in alveolar type II pneumocytes in relation to surfactant synthesis. Anat. Rec. 174: 289-310.

5. Young, S. L., D. F. Tierney. 1972. Dipalmitoyl lecithin secretion and metabolism by the rat lung. Am. J. Physiol. 222: 1539-1544.

6. Jobe, A. 1977. The labeling and biological half-life of phosphatidylcholine in subcellular fractions of rabbit lung. Biochim. Biophys. Acta. 489: 440-453.

7. Jobe, A., E. Kirkpatrick, and L. Gluck. 1978. Labeling of phospholipids in the surfactant and subcellular fractions of rabbit lung. J. Biol. Chem. 253: 3810-3816.

8. Adams, F. H., B. Towers, A. B. Osher, M. Ikegami, T. Fujiwara, and M. Nozaki. 1978. Effects of tracheal instillation of natural surfactant in premature lambs. I. Clinical and autopsy findings. Pediatr. Res. 12: 841-848.

9. Oyarzun, M. J., J. A. Clements, and A. Baritussio. 1980. 
Ventilation enhances pulmonary alveolar clearance of radioactive dipalmitoyl phosphatidylcholine. Am. Rev. Resp. Dis. 121: 709-721.

10. King, R. J., and H. Martin. 1980. Intracellular metabolism of the apoproteins of pulmonary surfactant in rat lung. J. Appl. Physiol. (Respir. Environ. Exercise Physiol.) 48: 812-820.

11. Jobe, A., M. Ikegami, T. H. Glatz, Y. Yoshida, J. F. Padbury, and E. Diakomanolis. 1980. The duration and effectiveness of surfactant therapy. Pediatr. Res. 14: 600A.

12. Hallman, M., and L. Gluck. 1976. Phosphatidylglycerol in lung surfactant III. Possible modifier of surfactant function. J. Lipid Res. 17: 257-262.

13. Hallman, M., and B. L. Epstein. 1980. Role of myoinositol in the synthesis of phosphatidylglycerol and phosphatidylinositol in the lung. Biochem. Biophys. Res. Commun. 92: 1151-1159.

14. Hallman, M., and L. Gluck. 1980. Formation of acidic phospholipids in rabbit lung during perinatal period. Pediatr. Res. 14: 1250-1259.

15. Bligh, E. G., and W. J. Dyer. 1979. A rapid method of total lipid extraction and purification. Can. J. Biochem. Physiol. 37: 911-917.

16. Kankare, P., and O. Suovaniemi. 1971. A simple method for determination of phosphate from thin-layer chromatographic plates. J. Chromatogr. 62: 485-486.

17. Mason, R. J., J. Nellenbogen, and J. A. Clements. 1976. Isolation of disaturated phosphatidylcholine with osmium tetroxide. J. Lipid Res. 17: 281-284.

18. Sottocasa, G. L., B. Kuylenstierna, L. Ernster, and A. Bergstrand. 1967. An electron transport system associated with the outer membrane of liver mitochondria: a biochemical and morphological study. J. Cell. Biol. 32: 415-438.

19. Lowry, O. H., N. J. Rosebrough, A. L. Farr, and R. J. Randall. 1951. Protein measurements with the Folin phenol reagent. J. Biol. Chem. 193: 265-275.

20. Hallman, M., B. L. Epstein, and L. Gluck. 1980. Dynamic state of surfactant phospholipids: Study on turnover using selective inhibition of phosphatidylglycerol synthesis in adult rabbit. Pediatr. Res. 14: 643A.

21. Mason, R. J., G. Huber, and M. Vaughan. 1972. Synthesis of dipalmitoyl lecithin by alveolar macrophages. $J$. Clin. Invest. 51: 78-83.

22. Matsuzawa, Y., B. J. H. M. Porthuis, and K. Y. Hostetler. 1978. Mechanism of phosphatidylinositol stimulation of lysosomal bis(monoacylglyceryl) phosphate synthesis. $J$. Biol. Chem. 253: 6650-6653.
23. Gil, J., and M. Magno. 1980. Fusion of pinocytotic vesicles in liquid filled lungs: A mechanism of cellular damage. Expt. Lung. Res. 1: 43-56.

24. Oyarzun, M. J., and J. A. Clements. 1978. Control of lung surfactant by ventilation, adrenergic mediators, and prostaglandins in the rabbit. Am. Rev. Respirat. Dis. 117: 879-891.

25. Wyszogrodski, I., K. Kyei-Aboagye, H. W. Taeusch, and M. Avery. 1975. Surfactant inactivation by hyperventilation: Conservation by end-expiratory pressure. J. Appl. Physiol. 38: 461-466.

26. McClenahan, J. B., and A. Urtnowski. 1967. Effect of ventilation on surfactant, and its turnover rate. J. Appl. Physiol. 23: 215-220.

27. Niden, A. H. 1967. Bronchiolar and large alveolar cell in pulmonary phospholipid metabolism. Science (Wash. D. C.). 158: 1323-1324.

28. DiAugustine, R. P. 1974. Lung concentric laminar organelle. Hydrolase activity and compositional analysis. J. Biol. Chem. 249: 584-593.

29. Heath, M. F., and W. Jacobson. 1976. Phospholipases $A_{1}$, and $A_{2}$ in lamellar inclusion bodies of the alveolar epithelium of rabbit lung. Biochim. Biophys. Acta. 441: 443-452.

30. Johnston, J. M., G. Reynolds, M. B. Wylie, and P. C. MacDonald. 1978. The phosphohydrolase activity in lamellar bodies and its relationship to phosphatidylglycerol and lung surfactant formation. Biochim. Biophys. Acta. 531: 65-71.

31. Gil, J., and O. K. Reiss. 1973. Isolation and characterization of lamellar bodies and tubular myelin from rat lung homogenates. J. Cell Biol. 58: 152-171.

32. Williams, M. C. 1977. Conversion of lamellar membranes into tubular myelin in alveoli of fetal rat lungs. J. Cell Biol. 72: 260-277.

33. Thet, L. A., L. Clerch, G. D. Massaro, and D. Massaro. 1979. Changes in sedimentation of surfactant in ventilated excised rat lungs. J. Clin. Invest. 64: 600-608.

34. Van Golde, L. M. G., V. Oldenborg, M. Post, and J. H. Batenburg. 1980. Phospholipid transfer proteins in rat lung. Identification of a protein specific for phosphatidylglycerol. J. Biol. Chem. 255: 6011-6013.

35. Bangham, A. D., C. J. Morley, and M. C. Phillips. 1979. The physical properties of an effective lung surfactant. Biochim. Biophys. Acta. 573: 552-556.

36. Jacob, J., M. Hallman, and L. Gluck. 1980. Phosphatidylinositol and phosphatidylglycerol enhance surface active properties of lecithin. Pediatr. Res. 14: 644A. 